\title{
Pembangunan Berbasis Masyarakat Di Kecamatan Kampar Kabupaten Kampar
}

\author{
${ }^{1}$ Surya Dailiati, ${ }^{2}$ Hernimawati, ${ }^{3}$ Sudaryanto \\ ${ }^{123}$ Fakultas Ilmu Administrasi, Universitas Lancang Kuning, Indonesia
}

e-mail: surya-dailiati@unilak.ac.id

\begin{abstract}
Abstrak
Kabupaten Kampar merupakan salah satu kabupaten yang ada di Provinsi Riau. Kabupaten ini termasuk daerah yang memiliki wilayah yang sangat luas di bandingkan dengan kabupaten/kota lainnya di Provinis Riau. Terbukti sejak era resformasi dari Kabupaten Kampar telah berhasil di mekarkan sejumlah daerah yakni Kabupaten Rokan Hulu, Kabupaten Pelalawan dan sebagian Kabupaten Kuantan Singingi serta sebagian Kabupaten Rokan Hilir. Dari pengamatan yang dilakukan ternyata di Kecamatan Kampar Kabupaten Kampar terdapat permasalahan yang perlu diselesaikan yakni terdapat madrasyah yang digunakan untuk siswa belajar dalam keadaan kurang layak dimana dinding dan atapnya rusak. Kemudian lapangan sepak bola yang kurang terawat sehingga bersemak dan hutan lindung yang belum terkelola dengan baik sesuai dengan kearifan lokal. Oleh karena itu dilakukan penelitian, untuk pemecahan masalahnya menggunakan teori Tim Delivery dalam Aprillia Theresia dkk (2014 halaman 220). Pembangunan berbasis masyarakat mencakup; seleksi lokasi, sosialiasi, proses dan pemandirian masyarakat. Dari kegiatan penelitian yang dilakukan diketahui bahwa pembangunan berbasis masyarakat di Kecamatan Kampar Kabupaten Kampar sudah berjalan dengan namun masih diperlukan perbaikan-perbaikan. Hal-hal yang sudah berjalan dengan meliputi seleksi lokasi, sosialisasi pembangunan berbasis masyarakat dan proses pembangunan berbasis masyarakat. Sedangkan yang perlu menjadi perbaikan kedepannya adalah pemandirian masyarakat.
\end{abstract}

Keywords: Pembangunan, Berbasis dan Masyarakat

\begin{abstract}
Kampar Regency is one of the regencies in Riau Province. This regency is an area that has a very wide area compared to other regencies / cities in Riau Province. It has been proven since the reformation era of Kampar Regency that has succeeded in blossoming a number of regions, namely Rokan Hulu Regency, Pelalawan Regency and part of Kuantan Singingi Regency and part of Rokan Hilir Regency. From the observations made, it turns out that in Kampar District Kampar District there are problems that need to be resolved, namely the madrasyah used for students learning in a state of inadequacy where the walls and roof are damaged. Then the soccer field is poorly maintained so that the bushes and protected forests have not been managed properly according to local wisdom. Therefore, research is done, to solve the problem using the theory of Team Delivery in Aprillia Theresia et al (2014 page 220). Community-based development includes; site selection, socialization, process and community independence. From the research activities carried out it is known that community-based development in Kampar District, Kampar Regency is already underway but improvements are still needed. Things that have been going on include location selection, community-based development socialization and community-based development processes. While what needs to be improved in the future is community independence.
\end{abstract}

Kata Kunci : Development, Based and Community 


\section{PENDAHULUAN}

Kabupaten Kampar merupakan salah satu kabupaten yang ada di Provinsi Riau. Kabupaten ini termasuk daerah yang memiliki wilayah yang sangat luas di bandingkan dengan kabupaten/kota lainnya di Provinis Riau. Terbukti sejak era resformasi dari Kabupaten Kampar telah berhasil di mekarkan sejumlah daerah yakni Kabupaten Rokan Hulu, Kabupaten Pelalawan dan sebagian Kabupaten Kuantan Singingi serta sebagian Kabupaten Rokan Hilir.

Meski telah mengalami pemekaran beberapa kali namun kabupaten ini tetap memiliki luas wilayah yang sangat signifikan. Saat ini kabupaten Kampar memiliki 21 kecamatan salah satunya adalah Kecamatan Kampar. Kecamatan Kampar termasuk yang memiliki banyak desa dan kelurahan yakni 17 desa 1 kelurahan. Dengan banyaknya kelurahan dan desa tentu dalam pembangunannya memerlukan keterlibatan semua pihak terutama masyarakat sendiri. Artinya pembangunan yang dibuat harus berdasarkan ide-ide atau usulan dari masyarakat agar sesuai dengan keinginan atau aspirasi. Jika tidak maka manfaat pembangunan tidak akan dirasakan oleh masyarakat.

Pembangunan yang melibatkan masyarakat untuk saat ini sudah seharusnya dilaksanakan baik secara botton up (bawah-atas) maupun top down (atas bawah). Apalagi bagi Kecamatan Kampar yang menjadi jalur perlintasan nasional yang menghubungkan Provinsi Riau dengan Provinsi Sumatera Barat tentu pembangunan yang dilaksanakan akan menjadi banyak sorotan berbagai pihak. Tidak hanya pembangunan fisik, pembangunan manusia dan alam turut menjadi perhatian. Ketiga pembangunan ini saling berhubungan karena memang menjadi kebutuhan pokok yang menunjang lainnya. Pembangunan fisik wajib dipenuhi karena ia merupakan wadah bagi manua beraktifitas. Pembangunan manusia diperlukan agar menghasilkan masyarakat yang cerdas, sejahtera sesuai dengan Undang Undang Dasar 1945. Kemudian pembangunan alam atau lingkungan agar kehidupan tetap berjalan dengan lestari, karena jika alam rusak maka dampak negatifnya akan menimpa manusia itu sendiri.

Pembangunan yang dilaksanakan di Kecamatan Kampar sendiri ada yang desa dan ada yang di kelurahana. Dari pengamatan yang dilakukan ternyata di Kecamatan Kampar Kabupaten Kampar terdapat permasalahan yang perlu diselesaikan. Permasalahan tersebut misalnya:

a) Terdapat madrasyah yang digunakan untuk siswa belajar dalam keadaan kurang layak dimana dinding dan atapnya rusak.

b) Lapangan sepak bola yang kurang terawat sehingga bersemak.

c) Hutan lindung yang belum terkelola dengan baik sesuai dengan kearifan lokal.

Konsep administrasi dapat diartikan sebagai suatu proses pengorganisasian tugas-tugas dan kegiatan dari berbagai tingkatan dan jenis pekerjaan secara sistematik dalam organisasi. Proses administrasi secara hierarki mengerjakan tiga fungsi utama, yaitu (1) fungsi pengarahan organisasi yang berkaitan dengan proses perencanaan jangka panjang, (2) fungsi manajemen organisasi yang berkaitan dengan upaya mempertahankan organisasi sebagai suatu pekerjaan yang terus berlangsung lama, seperti memberikan bahan, sarana, instruksi dan peciptaan iklim yang diperlukan oleh staf teknis atau professional yang terlibat dalam proses produksi, (3) fungsi pengawas, yaitu kontroling dan evaluasi atasan kepada bawahan dengan cermat, tegas dan dapat dipertangungjawabkan dengan baik dan benar, (Asep, 2012).

Sedangkan menurut Tim Delivery dalam Aprillia Theresia dkk (2014 halaman 220), pembangunan berbasis masyarakat mencakup;

1) Seleksi lokasi

2) Sosialiasi

3) Proses

4) Pemandirian masyarakat 
Tujuan penelitian ini adalah untuk mengetahui bagaimana pembangunan berbasis masyarakat berjalan di Kecamatan Kampar Kabupaten Kampar. Kemudian untuk mengetahui apa saja hambatan dalam pelaksanaan pembangunan berbasis masyarakat di Kecamatan Kampar Kabupaten Kampar.

\section{METODE}

Penelitian dilakukan di Kantor Camat Kampar Kabupaten Kampar. Informan ataupun narasumber dalam penelitian ini adalah Camat, Sekretaris Camat, Kepala Seksi Pembangunan, Staf Kecamatan dan Kepala Desa. Sumber dan jenis data dalam penelitian ini adalah primer dan sekunder. Data Primer adalah data yang kumpulkan langsung dari informan yang terpilih dalam penelitian ini. Dalam kegiatan penelitian kualitatif yang menjadi Aparatur pemerintah informasi adalah para informan (subjek) yang kompeten, mempunyai relevansi dengan setting sosial yang diteliti. Sedangkan tempat yang menjadi elemen dari situasi sosial adalah situasi dan kondisi lingkungan tempat yang berkaitan dengan permasalahan penelitian. (Iskandar, 2009:113). Data sekunder adalah data yang diperoleh dari literaturliteratur, media cetak, atupun media elektronik, dokumen administrasi, penelitian sebelum atau lainnya yang terkait. Penghimpunan data dilakukan berdasarkan observasi, wawancara dan dokumentasi. Data yang telah terkumpul berdasarkan jenis dan bentuk data, untuk selanjutnya data dianalisa secara deskriptif kualitatif, yakni mengungkapkan kejadian atau fakta, keadaan, fenomena, variabel dan keadaan yang terjadi saat penelitian berlangsung dengan menyuguhkan apa yang sebenarnya terjadi. Penelitian ini menafsirkan dan menguraikan data yang bersangkutan dengan situasi yang sedang terjadi.

\section{HASIL DAN PEMBAHASAN}

\subsection{Hasil}

Pembangunan berbasis masyarakat menurut Theresia dkk (2015), yaitu pemberian kesempatan kepada kelompok lapisan bawah (grassroot) untuk bersuara dan menentukan sendiri pilihan-pilihannya (voice and choice). Hal ini ter kaitannya dengan aksesbilitas informasi, keterlibatan dalam pemenuhan kebutuhan serta partisipasi dalam keseluruhan proses pembangunan, bertanggung-gugat (akuntabilitas publik) dan penguatan kapasitas lokal.

Dari kegiatan penelitian yang dilakukan diketahui bahwa pembangunan berbasis masyarakat di Kecamatan Kampar Kabupaten Kampar sudah berjalan dengan namun masih diperlukan perbaikanperbaikan. Hal-hal yang sudah berjalan dengan meliputi seleksi lokasi, sosialisasi pembangunan berbasis masyarakat dan proses pembangunan berbasis masyarakat. Sedangkan yang perlu menjadi perbaikan kedepannya adalah pemandirian masyarakat.

Untuk proses pembangunan berbasis masyarakat mencakup kajian keadaan pedesaan partisipasif, pembangunan berbasis kelompok, penyusunan rencana dan pelaksanaan kegiatan serta monitoring dan evaluasi partisipasif. Dari segi penyusunan rencana juga termasuk lemah karena keahlian dari para aparatur sipil negara (ASN) yang belum terampil. Hal ini dibuktikan dengan masih banyaknya ASN yang masih berpendidikan SMA/ sederajat. Dari 25 orang ASN, 16 orang adalah SMA.

Oleh karena itu ASN yang ada di Pemerintah Kecamatan Kampar mesti ditingkatkan pendidikannya agar memiliki pengetahuan dan keahlian yang memadai. Dengan demikian maka segala kegiatan pembangunan yang dijalankan sudah berbasis masyarakat. Kalau sudah berbasis masyarakat, maka tidak akan ditemukan lagi keberatan-keberatan atas berbagai program dan kegiatan yang dibuat antara pemerintah dan masyarakat. 


\subsection{Pembahasan}

Pembangunan berbasis masyarakat dapat dipandang sebagai suatu proses perubahan terencana. Dalam hal ini, untuk Pemerintah Kecamatan Kampar Kabupaten Kampar sudah melibatkan berbagai komponen masyarakat sesuai dengan ketentuan yang berlaku.

\section{Seleksi Lokasi/ Wilayah}

Seleksi wilayah dilakukan sesuai dengan kriteria yang disepakati oleh lembaga, pihak-pihak terkait dan masyarakat. Penetapan kriteria penting agar, pemilihan lokasi dilakukan sebaik mungkin, sehingga tujuan pembangunan berbasis masyarakat akan tercapai seperti yang diharapkan.

Menurut Sekretaris Camat Kabuaten Kampar, Ali Sastro Amijoyo, Pemerintah Kecamatan Kampar senantiasa berupaya memenuhi semua keinginan masyarakat terkait dengan lokasi yang akan dibangun. Namun berdasarkan kondisi keuangan yang ada maka tidak mungkin semua dipenuhi oleh Pemerintah Kecamatan Kampar, maka akan ada skala prioritas.

Sementara menurut Staf Kecamatan Kampar, Mulyadi, biasanya masyarakat selalu minta disamaratakan dalam pembangunan. Artinya, jika suatu lokasi mendapatkan proyek pembangunan, maka lokasi/ desa yang lain juga minta diperlakukan sama. Padahal ini sesuatu yang tidak mungkin dan sulit, mengatasinya semua desa mesti mendapatkan proyek pembangunan meskipun dengan anggaran yang sangat minim.

Seleksi lokasi yang dilakukan oleh Pemerintah Kecamatan Kampar tentu melihat kepada azas pemerataan pembangunan. Dalam hal ini dimana lokasi yang belum pernah dilaksanakan pembangunan akan diprioritaskan, seperti dalam menunjang ahlak dan moral dilaksanakan penyelesaian pembangunan mushalla MTSN Naumbai di Desa Naumbai. Kemudian peningkatan sumber daya manusia dilaksanakan pembangunan ruang kelas SMA Negeri 1 Kampar di Kelurahan Air Tiris. Selanjutnya pembangunan yang menunjang ekonomi kerakyatan, dilaksanakan pembangunan irigasi pertanian Kelomk Tani Saiyo di Desa Pulau Sarak. Pembangunan irigasi ini dilaksanakan sepanjang 1.000 meter.

\section{Sosialisasi Pembangunan Berbasis Masyarakat}

Sosialisasi merupakan upaya mengkomunikasikan kegiatan untuk menciptakan dialog dengan masyarakat. Melalui sosialisasi akan membantu untuk untuk meningkatkan pemahaman masyarakat dan pihak terkait tentang program dan atau kegiatan pembangunan berbasis masyarakat yang telah direncanakan. Proses sosialiasi menjadi sangat penting, karena akan menentukan minat atau ketertarikan masyarakat untuk berpartisipasi (berperan dan terlibat) dalam program pemberdayaan masyarakat yang dikomunikasikan.

Pemerintah Kecamantan Kampar Kabupaten kampar melakukan sosialisasi dalam bentuk rapat kecamatan yang dihadiri perwakilan Pemerintah Desa/ Kelurahan. Harapan sebenarnya tentu yang hadir adalah langsung kepala desa/ lurah, namun dalam prakteknya tidak jarang yang hadir adalah kepala urusan atau staf.

Dalam kegiatan sosialisasi dimulai dari penyampaian dasar hukum suatu kegiatan/ rencana kerja atau lainnya. Semuanya harus dibuat berdasarkan landasan hukum sehingga tidak menjadi masalah di kemudian hari. Kemudian penyampaian maksud dan tujuan kegiatan. Misalnya rencana kerja memiliki maksud mengidentifikasi sumber daya dan sumber dana pembangunan agar menjadi pedoman penyusunan rencana kerja anggaran Kecamatan Kampar.

Kemudian sosialisasi terhadap evaluasi pembangunan, apakah sudah berjalan sesuai maksud dan tujuan. Kegiatan ini perlu dilakukan agar tidak menimbulkan kesan negatif. Pengukuran evaluasi dilakukan sesuai dengan penetapan indikator agar seragam. Hal-hal yang disampaikan dalam sosialisasi tentunya sesuatu yang masih bersifat baru dengan tujuan agar semua pihak tahu, paham, pada akhirnya mau terlibat dalam kegiatan pembangunan. 
Terkadang ada kesan di masyarakat, bahwa pembangunan yang dilalukan tanpa sosialisasi, masyarakat tahu ada pembangunan ketika pembangunan itu dilaksanakan tanpa terlibat dalam usulan, hingga evaluasi. Sehingga masyarakat mau tidak mau dipaksa untuk menerima apa yang sudah ada. Menghindari hal ini maka Pemerintah Kecamatan Kampar Kabupaten Kampar senantiasa melakukan sosialisasi dengan melibatkan semua pihak dan pihak-pihak terkait.

\section{Proses Pembangunan Berbasis Masyarakat}

Sesuai dengan Undang-undang Nomor 17 Tahun 2003 tentang keuangan daerah dan Undangundang Nomor 25 tahun 2004 tentang pemerintahan daerah. Berdasarkan aturan tersebut maka pembangunan dibuat harus berdasarkan perencanaan, baik jangka pendek, menengah maupun panjang. Setiap satuan kerja perangkat daerah termasuk kecamatan perlu melaksanakan pembangunan berdasarkan perencanaan yang dibuat. Perencanaan ini juga berpedoman kepada rencana strategis satuan kerja perangkat daerah dan rencana kerja pembangunan daerah yang memuat informasi dana, tenaga kerka, fasilitas dan lain-lain.

Pada dasarnya hakikat pembangunan berbasis masyarakat adalah untuk meningkatkan kemampuan dan kemandirian masyarakat dalam meningkatkan taraf hidupnya. Dalam proses tersebut yang dilakukan di Kecamatan Kampar, masyarakat bersama-sama melakukan hal sebagai berikut:

a) Mengidentifikasi dan mengkaji potensi wilayah, permasalahan serta peluang-peluangnya. Di Kecamatan Kampar terdapat destinasi pariwisata relisi yakni mesjid jamik yang belum didukung pembangunan infrastrukturnya atau akses ke lokasi tersebut. Meskipun untuk daerah lain sudah ada dilakukan seperti pembangunan jaringan listrik desa.

b) Menyusun rencana kegiatan kelompok berdasarkan hasil kajian, meliputi; pemprioritasan dan analisa masalah, identifikasi alternatif pemcahan masalah, identifikasi sumber daya yang tersedia dan pembangunan berbasis rencana kerja. Untuk Pemerintah Kecamatan Kampar hal yang terjadi misalnya ada kegiatan yang prioroitas seperti pengaspalan jalan desa. Kemudian yang belum disepakati yakni pembangunan turap di Desa Tanjung Rambutan. Kegiatan yang prioritas dan yang belum disepakati ini selanjutnya di rekap semua dalam suatu rencana kerja termasuk di dalamnya pembangunan Kantor Camat Kampar yang sampai saat ini belum terealisasi.

c) Langkah selanjutnya yang dilakukan adalah menerapkan rencana kerja. Dalam hal ini rencana yang sudah disusun bersama dengan dukungan fasilitas dari pendamping.

\section{Pemandirian Masyarakat}

Pada dasarnya pembangunan tidak hanya dibebankan kepada pemerintah perlu juga keterlibatan masyarakat dalam berbagai aspeknya. Tanpa keterlibatan masyarakat dan kemandirian masyarakat, kenyatannya banyak pembangunan yang mubazir. Maka, berpegang pada prinsip pembangunan berbasis masyarakat yang bertujuan untuk memandirikan masyarakat dan meningkatkan taraf hidupnya, maka arah pemandirian masyarakat adalah berupa pendampingan untuk menyiapkan masyarakat agar benar-benar mampu mengelola sendiri kegiatannya.

Untuk Kecamatan Kampar secara khusus tenaga pendamping belum ada, namun untuk Kabupaten Kampar secara umum sudah ada tenaga pendamping yang anggarannya berasal dari Kementerian Desa dan Pembangunan Daerah Tertinggal dan Transmigrasi. 
Tabel 1. Tenaga Pendamping Desa di Kabupaten Kampar

\begin{tabular}{rlc}
\hline No & Spesifikasi & Jumlah \\
\hline 1 & Tenaga Ahli & 6 \\
\hline 2 & Pendamping Pemberdayaan & 32 \\
\hline 3 & Tehnik Infrastruktur & 19 \\
\hline 4 & Lain-lain & 10 \\
\hline & Total & 67 \\
\hline
\end{tabular}

Bagi Pemerintah Kabupaten Kampar khususnya Kecamatan Kampar, Tenaga Pendamping Desa termasuk dalam instrumen percepatan kesejahteraan masyarakat. Hal ini sesuai dengan undang-undang nomor 6 tahun 2014 tentang desa telah mengatur bahwa pembangunan dan pemberdayaan masyarakat desa ditempuh melalui pendampingan atau Pendamping Desa. Dengan demikian pendampingan merupakan salah satu instrumen penting untuk mempercepat kemandirian dan kesejaheteraan masyarakat.

Berdasarakan kondisi yang ada ternyata masyarakat desa belum bisa bediri sendiri untuk memandirikan desa. Ini terlihat dalam penyusunan rencana kegiatan pembangunan hingga laporan pembangunan. Pembangunan berbasis masyarakat yang dilaksanakan masih banyak yang sifatnya proyek.

\section{KESIMPULAN}

Dari kegiatan penelitian yang dilakukan diperoleh kesimpulan bahwa pembangunan berbasis masyarakat di Kecamatan Kampar sudah dilaksanakan berdasarkan seleksi lokasi, sosialisasi dan prosesnya. Proses yang dimaksud adalah kajian, basis kelompok, perencanaan dan monitoring dan evaluasi. Sedangkan yang mejadi hambatan pembangunan berbasis masyarakat di Kecamatan Kampar adalah kurangnya komunikasi antara pemerintah dan masyarakat sehingga hasil pembangunan belum merubah kesejahteraan masyarakat.

\section{SARAN}

Saran yang perlu dilakukan adalah meningkatkan komunikasi antara pemerintah dan masyarakat dari awal penyusunan perencanaan pembangunan. Langkah selanjutnya yang harus dilakukan adalah meningkatkan monitoring dan evaluasi bersama sehingga memiliki pemahaman tujuan baik formal maupun non formal.

\section{DAFTAR PUSTAKA}

[1] Abu Ahmadi dan Noor Salimi, 2008, Dasar-Dasar Pendidikan Agama Islam, Bumi Aksara, Jakarta.

[2] Agus Dkk, 2012, Modul Monitoring Penegakan Hukum, ICW, Jakarta.

[3] Anggara Sahya. 2012. Perbandingan Administrasi Negara. CV Pustaka Setia, Bandung.

[4] Beddy Iriawan, 2012. Sistem Politik Indonesia, Rajawali Pers, Jakarta

[5] Chrisyanti, 2011, Pengantar Ilmu Administrasi, Prestasi Pustaka Publisher, Jakarta. 
[6] Danang Sunyoto dan Burhanuddin, 2011, Perilaku Organisasional, CAPS, Yogyakarta.

[7] Deddy Mulyadi, 2015. Studi Kebijakan Publik Dan Pelayanan Publik, Alfabeta, Bandung.

[8] Kaelan, 2010, Pendidikan Pancasila, Paradigma, Yogyakarta.

[9] MPR RI, 2012, Ketetapan MPR RI Nomor I/ MPR/ 2003 Tentang Peninjauan Kembali Materi dan Status Hukum Ketetapan MPR Sementara dan Ketetapan MPR RI Tahun 1960 -2002, Sekretariat Jenderal MPR RI, Jakarta

[10] Padmo Wahjono dan Nazaruddin Syamsuddin, 2009, Pengantar Ilmu Politik, PT Raja Grafindo Persada, Jakarta.

[11] Riant Nugroho dan Randy Wrihatnolo, 2011, Manajemen Perencanaan Pembangunan, Kompas Gramedia, Jakarta.

[12] Ridwan HR, 2010, Hukum Administrasi Negara, PT Raja Grafindo Persada, Jakarta.

[13] Siti Fajar dan Tri Heru, 2013, Manajemen Sumber Daya Manusia, UPP STIM YKPN, Yogyakarta.

[14] Subhan Sofhian dan Asep Sahid, 2011, Pendidikan Kewarganegaraan, Fokus Media, Bandung.

[15] Theresia dkk, 2014, Pembangunan Berbasis Masyarakat, Alfabeta, Bandung.

[16] Wibowo, 2010, Budaya Organisasi, Rajawali Pres, Jakarta.

[17] Yusuf Muri, 2014, Metode Penelitian; Kuantitatif Kualitatif dan Penelitian Gabungan, Prenada Media Grup, Jakarta. 